\title{
EPIDEMIOLOGIC CHARACTERIZATION OF ENDODONTIC DIAGNOSIS AND TREATMENT
}

\author{
Valeska Alvarado ${ }^{1}$, Gabriela Sepúlveda², Dylan Mariño ${ }^{3}$
}

\section{RESUMEN}

Objetive: To characterize the endodontic diagnosis and treatments performed during 2008-2011 at School of Dentistry, University of Andrés Bello, Chile.

Methos: Case series study comprising 632 endodontics clinical records, corresponding to 506 patients. Variables included were clinical and radiographic features of the tooth anatomy, and variables related to treatment. Statistics analysis was performed through Stata 11 software. For multivariate analysis, logistic regression model was used, including adjusted Odd ratio; $p<0.05$ was considered significative.

Results: The most frequent diagnosis were pulp necrosis and asymptomatic irreversible pulpitis. Endodontic treatments were more common in women, in upper maxilla, in molars and premolars; in general, the main biomechanical preparation technique is manual and hybrid, except in molars, where mechanized technique is more common; the most used master apical file was file $\# 40$, and in upper incisors, \#60; lateral condensation obturation technique was the most frequently used. A good prognosis was related with lateral and vertical obturation technique, and absence of soft tissue alterations.

Conclusions: This study brought relevant information about working lengths for each root canal for each tooth type. It related tooth type with the technique used for the coronal two-thirds preparation and its instruments, obturation technique and informed about the master file used for each root canal, by means of cross tables. Also, it builds an estimation model for the postoperative prognosis
1. Asesor Odontológico Seremi de Salud Aysén Coyhaique, Chile.

2. Servicio Médico Odontológico Universidad de Playa Ancha, Chile.

3. Universidad Andres Bello, Chile.

\section{Correspondencia:}

\section{Gabriela Sepúlveda}

Correo electrónico:

gsepulvedar05@gmail.com

\section{KEYWORDS:}

Endodontics; diagnosis; BMP 


\section{INTRODUCTION}

Endodontic treatment is a highly required option to lengthen the lifespan of teeth in the mouth. Different studies show high success rate in the outcomes of this treatment. ${ }^{1}$ In fact, evidence reports that endodontic treatment has a high frequency, from $1.2 \%$ to $23,0 \%$ of the total of dental treatments performed. ${ }^{2}$ This therapy progressively has incorporated more technology that has influenced the execution modalities, which is necessary to know. And according to our information search, there is evidence available about the characterization of endodontic treatments, evaluation of radiographic records or need for endodontic treatment, from many countries, but not from Chile. ${ }^{3,4}$ Epidemiological studies, like ours, that present information in detail of dental clinical records, can be of great value to improve knowledge about prevalence and distribution of patients who need endodontic treatment in a specific population. ${ }^{4}$

The purpose of this study is to characterize the endodontic diagnosis and treatments performed during 2008-2011 at School of Dentistry, University of Andrés Bello, Chile.

\section{MATERIALS AND METHODS}

Case series study, based on the evaluation of clinical records from patients who received endodontic treatment, performed at School of Dentistry, University of Andrés Bello, Chile by undergraduate and postgraduate students, during 2008--2011. The universe of this investigation consisted of 1310 general clinical records which passed through endodontics service according to the computer system; later, the search of the paper record allowed to find 950, of which 339 were excluded because they did not present specific endodontic records (which is made by each tooth), and also 99 because the patient did not end the treatment due to absence, need of surgery (apicectomy) or referral for extraction. A total of 632 endodontic records were reviewed, corresponding to 506 patients. And just for study and work lengths purposes, 31 were excluded due to incomplete data.

Data were extracted form endodontic clinical records; variables collected were: gender; type of treated tooth; clinical features of the tooth, including presence of cavities, dental fillings and its extension, crown fracture and dental mobility; periodontal pocket; radiographic anatomy of the root and root canals; presence of alterations in surrounding soft tissues; presence and features of associated pain and clinical pulp diagnosis according to nomenclature proposed by the American Association of Endodontics. ${ }^{5}$ Variables related to treatment included: opening technique, type of conductometry, type of biomechanical preparation and obturation, sessions of treatment, study length, working length, irrigating solutions used and master apical file. About prognosis, it was registered as good, dubious or poor.

Each variable codes was created and registered by only one person in an excel spreadsheet, in a period of 3 months, taking no more than 10 minutes for each clinical record, reviewing a media of 50 clinical records per week.

This study counted with the approval of investigation committee of the institution and the express permission of the authority of the dental clinics; it was carried out with confidential handling of the patient and treating dentist identifications, according to local norms. Statistical analysis was carried out through Microsoft Excel 2010, Stata 11 and Minitab 15 softwares. To qualitative variables, frequency and percentage were described. To quantitative, means and medians were described, with their respective confidence interval of $95 \%$. When qualitative variables were related, simple correspondence analysis was performed, showing Biplot projections charts of conditional frequencies, along with Chi square test. For multivariate analysis, logistic regression model was used, including adjusted Odd ratio; a significance level of $\mathrm{p}<0.05$ was considered.

\section{RESULTS}

None of the endodontic clinical records had $100 \%$ of data. There were $340(67,2 \%)$ female patients record and $166(32,8 \%)$ corresponding to men. 
There was a total of 632 teeth; it was observed that endodontically treated teeth were more common in the upper maxilla, with $63,7 \%$. Upper and lower molars and premolars were the most common treated teeth. Followed by upper incisors, canines, and finally lower incisors. (Figure 1)

Pain was present in $41,5 \%$ of patients. Of these, $61,1 \%$ of cases corresponded to induced by stimuli pain. The most common stimuli that caused pain was chewing $(34,9 \%$, followed by cold $(19,1 \%)$ and a combination of more than one stimuli $(46,0 \%)$. Other pain was a combination of spontaneous and provoked pain $(24,1 \%)$ and $14,8 \%$ was spontaneous pain only. When spontaneous, it presented sporadically in $59 \%$ of cases and was throbbing in a $23,1 \%$. About pain intensity, it was severe in $18,5 \%$ and moderate in $43,2 \%$. Pain was described as localized in $57,3 \%$.

Presumptive diagnosis for treated teeth were Pulp necrosis (32,1\%), Asymptomatic Irreversible Pulpitis (22\%), Previously initiated therapy (15\%), Previously treated (8,7\%), Normal Pulp (6,6\%), Symptomatic irreversible pulpitis $(2,1 \%)$, Reversible Pulpitis $(0,9 \%)$. Having $12 \%$ of cases that do not report the diagnosis.

When initiated endodontic treatment, 69,9\% of treated teeth received total elimination of cavities and/or old fillings. Electronic apex locator was used for odontometry in $85 \%$ of cases. Regarding number of root canals, 48, $4 \%$ of treated teeth presented a single duct; $24,5 \%$ presented 3 root canals; $16,6 \%$ had 2 ducts and, less frequently, $8,4 \%$ of teeth had 4 ducts. (Figure 2)

Clinical and radiographic features of reported teeth are summarized in Table I.

Table II shows that the coronal two-thirds preparation is performed with Gates Glidden drills in incisors, canines and premolars, but in molars mechanized system is more frequently used.

A statistically significant relationship was found amongst instrument used for coronal two-thirds preparation and tooth type (Chisquare: $\mathrm{X} 2=59,255$. d.f $=6 . \mathrm{p}<0,001)$. This analysis is subject to the use of $\mathrm{K}$ and $\mathrm{H}$ files, because the use of $\mathrm{K}$ files count is little.

Table II shows that in incisors, canines and premolars the most used biomechanical technique is manual; whereas in molars, hybrid technique is more frequent. Furthermore, a statistically significant relationship was found between biomechanical preparation technique and tooth type (Chi- square: $\mathrm{X} 2=61,570$. $\mathrm{df}=9$. $\mathrm{p}<0,001$. This analysis is subject to exclusion of straight root canals, because its count is zero.

Concerning irrigating solutions, $29 \%$ had a

Figure 1: Distribution of endodontically treated teeth.

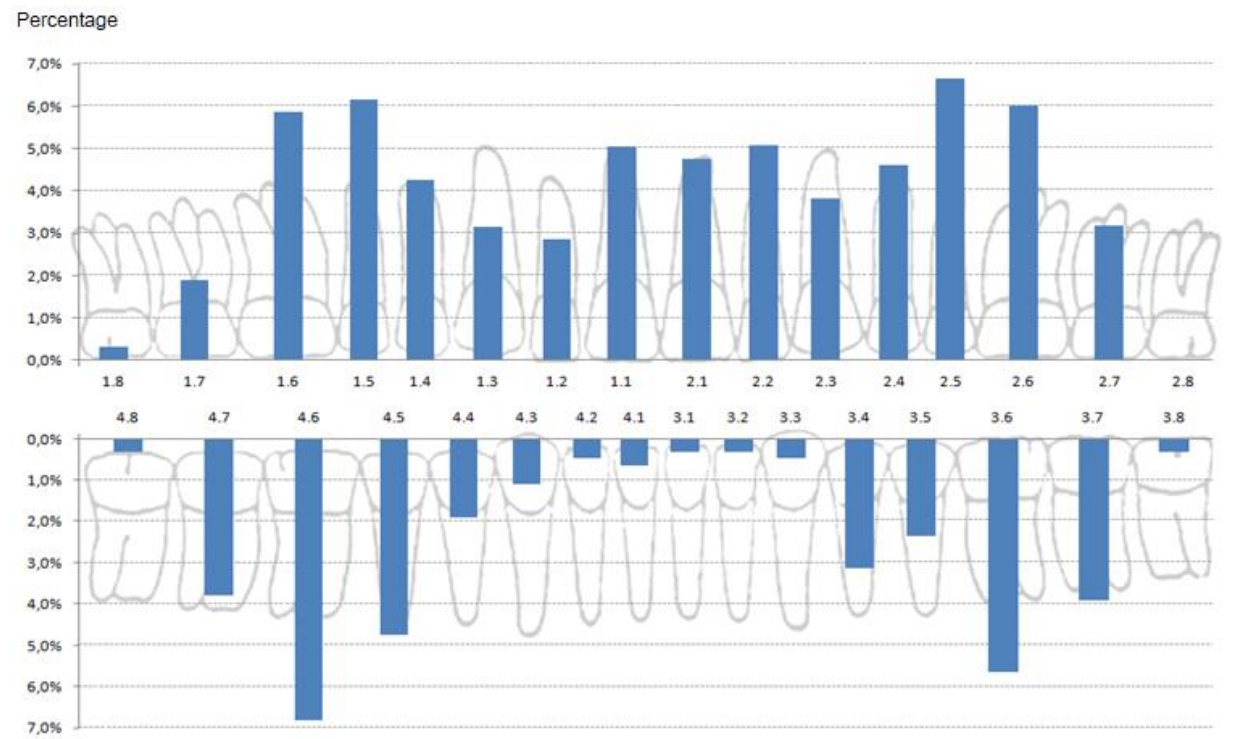


Figure 2: Distribution of working length medians

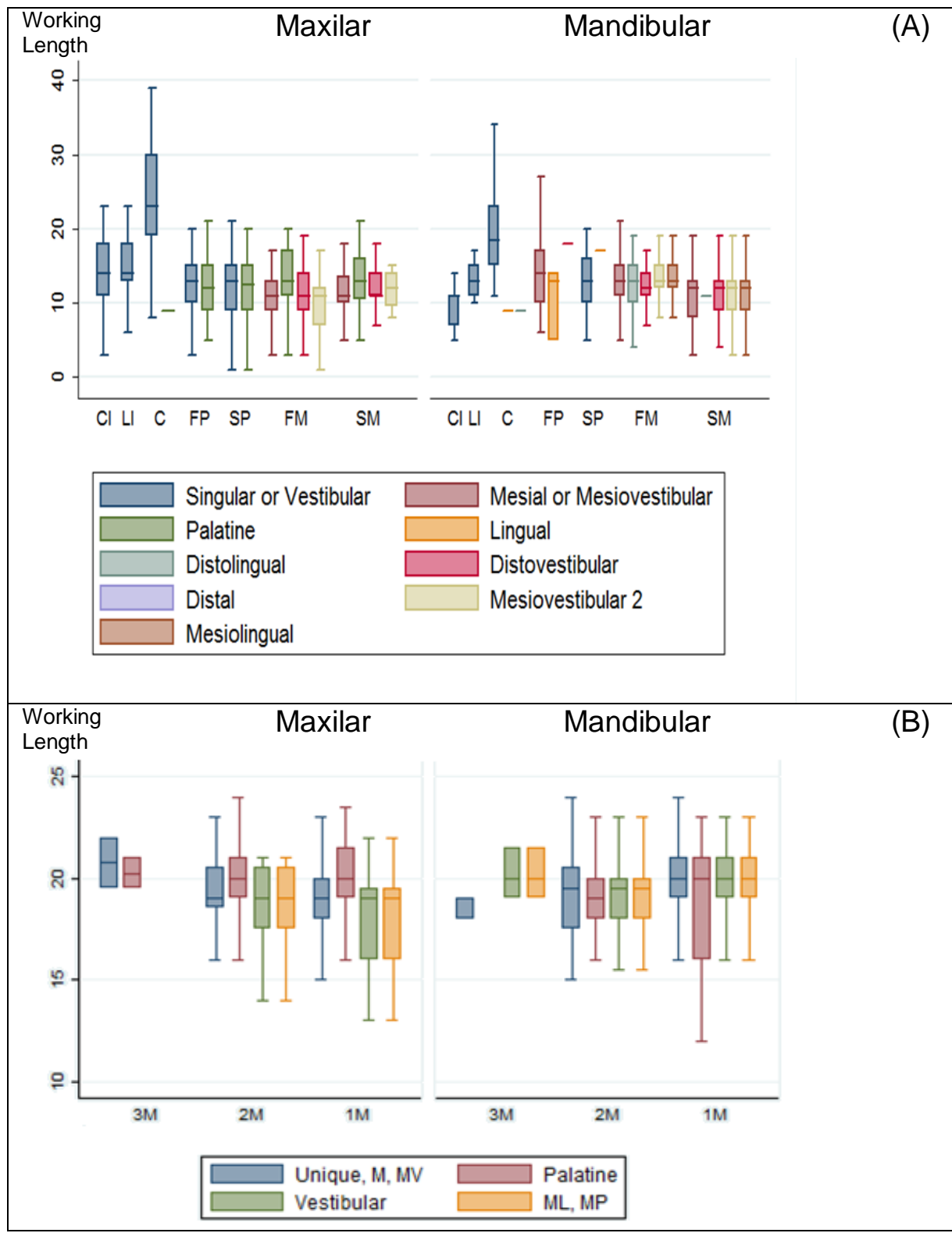

(A) Distribution of working length medians in anterior teeth and premolars. Excludes outside values. CI: Central Incisor; L: Lateral Incisor; C: Central; FP: First Premolar; SP: Second Premolar; FM: First Molar; SM: Second Molar (B) Distribution of working lengths medians in molars. Excludes outside values. 3M: Third Molar; 2M: Second Molar; 1M: First Molar

combination of clorhexidine, saline, sodium hypochlorite and chelating; $18,9 \%$ had the same combination without clorhexidine; $12,4 \%$ used physiologic saline and sodium hypochlorite only, and $14,2 \%$ used other combinations.

Table III shows that the most frequently used file in incisors is number $60(0,6 \mathrm{~mm})$; also, file $\mathrm{n}^{\circ} 40(0,4 \mathrm{~mm})$ is the most used before the obturation in every root canal type registered.
Table IV shows that lateral condensation technique is the most used, with a percentage exceeding more than a half of the total in all tooth types.

It was registered that the most frequent duration of treatment was 2 or 3 sessions, with $40,3 \%$ and $32,7 \%$ of the total respectively. Also, frequencies projections shown in Figure 4 explain a $88.81 \%$ of the total variability of data, according to the type of tooth and number 
of sessions. Thus, it was found that incisors and canines tend to be treated in 1 or 2 sessions, premolars between 2 and 4 sessions and finally molars, between 3 and 5 or more sessions, so a statistically significant relationship was found between tooth type and the number of sessions (Chi-Square. $\mathrm{X} 2=$ $31.086 \mathrm{DF}=12 . \mathrm{p}=0,002)$.

Once discharged from the treatment, the

Table I: Clinical and radiographic features found in the evaluation of teeth to be treated

\begin{tabular}{|c|c|c|c|c|c|}
\hline \multirow{2}{*}{\begin{tabular}{|l|} 
Cavities and its extent \\
\end{tabular}} & $\mathrm{N}$ & \multirow[t]{2}{*}{$\%$} & \multicolumn{2}{|r|}{$\mathrm{N}$} & \multirow[t]{2}{*}{$\%$} \\
\hline & & & \multicolumn{2}{|c|}{ Dental fillings and its extent } & \\
\hline Deep & 98 & 47,6 & Extensive & 179 & 61,9 \\
\hline Deep complicated & 95 & 46,1 & Medium extent & 91 & 31,5 \\
\hline Superficial & 13 & 6,3 & Small & 19 & 6,6 \\
\hline Total & 206 & 100 & Total & 289 & 100 \\
\hline \multicolumn{3}{|l|}{ Soft tissues alterations } & \multicolumn{3}{|c|}{ Features of the volume increase } \\
\hline Unaltered & 334 & 75,7 & Soft & \multirow{2}{*}{$\begin{array}{l}9 \\
15\end{array}$} & \multirow{2}{*}{$\begin{array}{l}21,4 \\
35,7\end{array}$} \\
\hline \multirow{2}{*}{$\begin{array}{l}\text { Only a fistula is present } \\
\text { Fistula and increase in } \\
\text { volume }\end{array}$} & 36 & 11,8 & & & \\
\hline & 16 & & Located & 11 & 26,2 \\
\hline Increase in volume & 26 & 5,9 & Located and hard & 5 & 11,9 \\
\hline Pain on palpation & 21 & 4,8 & Other (Diffuse, hard) & 2 & 4,8 \\
\hline Change in color & 8 & 1,8 & & & \\
\hline Total & 441 & 100 & Total & 42 & 100 \\
\hline Fistula condition & & & Crown fracture & & \\
\hline Active & 35 & 67,3 & Present & 67 & 54,5 \\
\hline Inactive & 17 & 32,7 & Absent & 56 & 45,5 \\
\hline Total & 52 & 100 & Total & 123 & 100 \\
\hline Dental root morphology & & & Pulp chamber featuı & & \\
\hline Normal Apex & 228 & 66,5 & Normal & 221 & 40,9 \\
\hline Apical curvature & 104 & 23,6 & Partial obturation & 85 & 16,5 \\
\hline Double contour & 21 & 4,8 & Calcified & 77 & 14,9 \\
\hline External root resorption & 13 & 3,0 & Wide & 74 & 14,3 \\
\hline Double curvature & 7 & 1,6 & Not observable & 62 & 12 \\
\hline Dilaceration & 5 & 1,1 & Other & 7 & 1,4 \\
\hline Hipercementosis & 2 & 0,5 & & & \\
\hline Total & 440 & 100 & Total & 516 & 100 \\
\hline Root canal morphology on $x$ & -ray & & Bone resorption deg & ree & \\
\hline Apparently straight & 177 & 33,5 & Without resorption & 279 & 56,3 \\
\hline Apparently straight and wide & 32 & 6 & Discrete & 118 & 23,8 \\
\hline $\begin{array}{l}\text { Apparently straight and } \\
\text { narrow }\end{array}$ & 24 & 4,5 & Moderate & 69 & 13,9 \\
\hline Curved & 94 & 17,8 & Vertical & 20 & 4 \\
\hline Curved and wide & 15 & 2,8 & Severe & 10 & 2 \\
\hline Curved and narrow & 19 & 3,6 & Total & 496 & 100 \\
\hline Wide & 29 & 5,5 & Periodontal pocket & & \\
\hline Narrow & 55 & 10,4 & Present & 23 & 15,1 \\
\hline Obtured & 37 & 7 & Absent & 129 & 84,5 \\
\hline Calcified & 12 & 2,3 & & & \\
\hline Other & 35 & 6,6 & & & \\
\hline Total & 529 & 100 & Total & 152 & 100 \\
\hline
\end{tabular}

prognosis was good in $97.8 \%$ of cases. A model of multiple logistic regression was constructed with all variables listed above to estimate the probability of having a good prognosis, resulting in only three explanatory variables which were: lateral sealing technique (OR 3.13), vertical shutter technique (OR 2.69) and soft tissue injury (OR -2.08). 
Table II: Distribution of tooth type and coronal two-thirds preparation instrument used and biomechanical preparation technique used.

\begin{tabular}{|lllllll|}
\hline Initials & & \multicolumn{4}{c}{ Tooth Tipe } & Total \\
\cline { 3 - 6 } & & Incisors & Canines & Premolars & Molars \\
\hline GG & Coronal 2/3 preparation & & & & \\
HL & H Files Glidden Drills & $69(71 \%)$ & $32(64 \%)$ & $100(65 \%)$ & $59(37 \%)$ & $260(56 \%)$ \\
Pro & Mechanized & $10(10 \%)$ & $7(14 \%)$ & $9(6 \%)$ & $7(4 \%)$ & $33(7 \%)$ \\
KL & K Files & $17(18 \%)$ & $11(22 \%)$ & $45(29 \%)$ & $93(58 \%)$ & $166(36 \%)$ \\
& Total & $1(1 \%)$ & $0(0 \%)$ & $1(1 \%)$ & $2(1 \%)$ & $4(1 \%)$ \\
CM & Conventional Manual (K files) & $40(37 \%)$ & $19(40 \%)$ & $63(34 \%)$ & $30(17 \%)$ & $152(29 \%)$ \\
MR & Mechanized (Rotatory) & $7(6 \%)$ & $5(10 \%)$ & $23(12 \%)$ & $48(28 \%)$ & $83(16 \%)$ \\
SRC & Straight Root Canals & $18(17 \%)$ & $9(19 \%)$ & $20(11 \%)$ & $0(0 \%)$ & $47(9 \%)$ \\
CC & Apparently cuerved canals & $22(20 \%)$ & $9(19 \%)$ & $44(24 \%)$ & $22(13 \%)$ & $97(19 \%)$ \\
MM & Mechanized and Manual (Hybrid) & $22(20 \%)$ & $6(13 \%)$ & $37(20 \%)$ & $72(42 \%)$ & $137(27 \%)$ \\
& Total & $109(100 \%)$ & $48(100 \%)$ & $187(100 \%)$ & $172(100 \%)$ & $516(100 \%)$ \\
\hline
\end{tabular}

Table III: Distribution of Master Apical File used

\begin{tabular}{|c|c|c|c|c|c|c|c|c|c|c|c|c|c|c|c|c|}
\hline \multirow{3}{*}{ MAF } & \multicolumn{6}{|c|}{ Single Root Canal } & \multicolumn{4}{|c|}{ Palatine Root Canal } & \multicolumn{6}{|c|}{ Molares } \\
\hline & \multicolumn{2}{|c|}{ Incisisors } & \multicolumn{2}{|c|}{ Canines } & \multicolumn{2}{|c|}{ Premolars } & \multicolumn{2}{|c|}{ Premolars } & \multicolumn{2}{|c|}{ Molars } & \multicolumn{2}{|c|}{$\begin{array}{l}\text { MV Root } \\
\text { canal }\end{array}$} & \multicolumn{2}{|c|}{$\begin{array}{l}\text { Distal root } \\
\text { canal }\end{array}$} & \multicolumn{2}{|c|}{$\begin{array}{l}\text { ML/MP } \\
\text { Root canal }\end{array}$} \\
\hline & $\mathrm{n}$ & $\%$ & $\mathrm{n}$ & $\%$ & $\mathrm{n}$ & $\%$ & $\mathrm{n}$ & $\%$ & $\mathrm{n}$ & $\%$ & $\mathrm{n}$ & $\%$ & $\mathrm{n}$ & $\%$ & $\mathrm{n}$ & $\%$ \\
\hline $\begin{array}{l}20 \\
(\mathrm{~F} 1)\end{array}$ & 0 & 0 & 0 & 0 & 0 & 0 & 0 & 0 & 0 & 0 & 3 & 1 & 0 & 0 & 1 & 1 \\
\hline $\begin{array}{l}25 \\
(\mathrm{~F} 2)\end{array}$ & 0 & 0 & 1 & 2 & 5 & 3 & 5 & 7 & 6 & 5 & 20 & 10 & 15 & 9 & 15 & 13 \\
\hline $\begin{array}{l}30 \\
(\mathrm{~F} 3)\end{array}$ & 4 & 3 & 2 & 4 & 12 & 6 & 3 & 4 & 15 & 13 & 34 & 17 & 23 & 13 & 21 & 18 \\
\hline 35 & 4 & 3 & 1 & 2 & 11 & 6 & 10 & 14 & 11 & 9 & 55 & 27 & 28 & 16 & 31 & 26 \\
\hline 40 & 17 & 14 & 15 & 29 & 68 & 34 & 30 & 42 & 29 & 24 & 69 & 34 & 65 & 38 & 39 & 33 \\
\hline 45 & 19 & 16 & 7 & 13 & 51 & 26 & 14 & 20 & 21 & 18 & 15 & 7 & 24 & 14 & 8 & 7 \\
\hline 50 & 18 & 15 & 8 & 15 & 30 & 15 & 5 & 7 & 24 & 20 & 4 & 2 & 11 & 6 & 0 & 0 \\
\hline 55 & 7 & 6 & 10 & 19 & 8 & 4 & 3 & 4 & 5 & 4 & 1 & 0 & 1 & 1 & 1 & 1 \\
\hline 60 & 31 & 26 & 7 & 13 & 7 & 4 & 1 & 1 & 8 & 7 & 0 & 0 & 6 & 3 & 1 & 1 \\
\hline 70 & 8 & 7 & 1 & 2 & 3 & 2 & 0 & 0 & 0 & 0 & 0 & 0 & 0 & 0 & 0 & 0 \\
\hline 80 & 11 & 9 & 0 & 0 & 3 & 2 & 0 & 0 & 1 & 1 & 1 & 0 & 0 & 0 & 0 & 0 \\
\hline Total & 119 & 100 & 52 & 100 & 198 & 100 & 71 & 100 & 120 & 100 & 202 & 100 & 173 & 100 & 117 & 100 \\
\hline
\end{tabular}


Tabla IV: Distribution of tooth type and obturation technique used

\begin{tabular}{|llllll|}
\hline \multirow{2}{*}{ Obturation technique } & \multicolumn{2}{l}{ Tooth Type } & \multirow{2}{*}{ Total } \\
\cline { 2 - 5 } & Incisors & Canines & Premolars & Molars & \\
\hline Lateral condensation & $91(81 \%)$ & $47(87 \%)$ & $121(65 \%)$ & $96(53 \%)$ & $355(67 \%)$ \\
Vertical condensation & $9(8 \%)$ & $3(6 \%)$ & $13(7 \%)$ & $5(3 \%)$ & $30(6 \%)$ \\
Lateral and vertical condensation & $3(3 \%)$ & $2(4 \%)$ & $12(6 \%)$ & $14(8 \%)$ & $31(6 \%)$ \\
Thermoplastified & $1(1 \%)$ & $1(2 \%)$ & $13(7 \%)$ & $10(6 \%)$ & $25(5 \%)$ \\
Ultrasound & $0(0 \%)$ & $0(0 \%)$ & $7(4 \%)$ & $16(9 \%)$ & $23(4 \%)$ \\
Thermafil (Carriers) & $5(4 \%)$ & $1(2 \%)$ & $8(4 \%)$ & $18(10 \%)$ & $32(6 \%)$ \\
Hybrid (lateral condensation and & $1(1 \%)$ & $0(0 \%)$ & $0(0 \%)$ & $8(4 \%)$ & $9(2 \%)$ \\
thermoplastified) & $2(2 \%)$ & $0(0 \%)$ & $11(6 \%)$ & $13(7 \%)$ & $26(5 \%)$ \\
Lateral condensation and ultrasound & $112(100 \%)$ & $54(100 \%)$ & $185(100 \%)$ & $180(100 \%)$ & $531(100 \%)$ \\
Total & & & & &
\end{tabular}

\section{DISCUSSION}

Regarding gender, the higher percentage of endodontic treatments was found in women $(66.1 \%)$. This was confirmed by a considerable number of studies which reported that women receive endodontic treatment more frequently than $\operatorname{men}^{2,4,6,7,8,9}$. This could be explained because women have more health concerns and seek more medical attention than men when facing health problems; in addition, they request more aesthetic treatments ${ }^{3,6}$. Also, in this study, upper maxilla was more treated, which is consistent with other reports 4,7,10,11,12. This could be explained by the greater aesthetic importance attributed to these teeth.

In the reviewed literature, it was reported that teeth that require most endodontic treatments are molars and premolars ${ }^{4,8,10,11,12}$; this coincides with our results, likely due to proximal caries that in these teeth evolve in a silent way and when symptoms appear often there is irreparable damage to the pulp. In the other hand, teeth that showed a lower frequency are lower incisors $(1.7 \%)$, which is consistent with other studies ${ }^{2,4,9,11}$ likely due to their location in a self-cleansing area, or because the accumulation of hard deposits that prevent tooth decay.

In working lengths registered in our study there is a clear tendency to the repetition of values according to the type of treated tooth, since incisors have a media of $20 \mathrm{~mm}$ [SD 2.47], premolars and molars a media of 19 $\mathrm{mm}$ [SD 2.23] and canines a media of $24 \mathrm{~mm}$ [SD 3.29]. Cohen ${ }^{13}$ indicated that with few exceptions, the length of most teeth varies between 19 and $25 \mathrm{~mm}$; we report more accurate estimates by tooth type and root canal, which could be used as a reference for the initial treatment if there is an urgent need and lack of resources.

In our study there were statistically significant differences between the techniques used for the preparation of the root canals according to the teeth type; in teeth with less complex anatomy is more commonly used the manual technique but when complexity is greater in anatomy there is an increase in the choice of mechanized technique. Regarding manual technique, Haapasalo ${ }^{14}$ indicates that it remains being the most common way of preparing root canals, however an increasing number of professionals would use mechanized techniques, since it allows them to complete the preparation in a quicker time and maintaining the original curvature of the ducts better than manual techniques.

This report shows that root canal preparation in any tooth reaches file \#40, except for the incisors in which master apical file would be file \#60. This coincides with Leonardo MR. ${ }^{15}$ who proposed that in broad and straight root canals, as the incisors, preparation should be \#45 to \#60.

Among the obturation techniques, the most frequent was lateral condensation technique alone or combined, showing a better prognosis. Soares ${ }^{16}$ indicates that lateral condensation technique can be used in all clinical cases, however in special situations other techniques provide better results, but should be used by 
trained professionals.

In our study the number of sessions is related to the tooth type which coincides with Quadros ${ }^{9}$ where teeth with more than two root canals often needed 4 or more sessions, a situation that can be explained by the complexity of treatment in these teeth since they have multiple canals with different anatomy.

A limitation faced by this study was the absence of the specific record of endodontics in clinical records of the institution, and the absence of data which could affect the results; however, the number of finally checked records is an important number.

In a subsequent investigation we suggest to relate diagnoses to preparation and obturation techniques; to monitor the clinical cases to confirm prognosis; and apply threedimensional imaging techniques for more accurate characterization of the teeth and development of treatments.

\section{CONCLUSION}

In conclusion, we found that the most frequent endodontics diagnosis are pulp necrosis and asymptomatic irreversible pulpitis. Endodontic treatments are more common in women, in upper maxilla, in molars and premolars; working lengths are conditioned to the tooth type and these can be used in reference when to not having imaging means; in general, the main biomechanical preparation technique is manual and hybrid, except in molars, where it is the mechanized technique; the most used master apical file is generally file \#40, and in upper incisors, \#60; lateral condensation obturation technique is the most frequently used, alone or in combination, which is associated to good prognosis. Instead, teeth with soft tissue alterations have dubious prognosis.

\section{CONFLICTS OF INTEREST}

No conclicts of interest

\section{REFERENCIAS}

[1] Wu MK, Shemesh H, Wesselink PR. Limitations of previously published systematic reviews evaluating the outcome of endodontic treatment. Int Endod J. 2009; 42(8):656-66.

[2] Hollanda, A.C, Alencar, A.G, Estrela, C.R, Bueno M.R; Estrela, C. Prevalence of Endodontically Treated Teeth in a Brazilian Adult Population. Braz Dent J. 2008; 19(4): 313-317.

[3] León P, Ilabaca MJ, Alcota M, González FE. Frecuencia de periodontitis apical en tratamientos endodónticos de pregrado. Rev. Clin. Periodoncia Implantol. Rehabil. Oral, 2011; 4(3); 126-129.

[4] Scavo R., Martinez R., Zmener O., DiPietro S., Grana D., Pameijer C.Frequency and distribution of teeth requiring endodontic therapy in an Argentine population attending a specialty clinic in endodontics. Int Dent J. 2011; 61: 257-260.

[5] AAE Consensus Conference Recommended Diagnostic Terminology. J Endod, 2009; 35 (12): 1634.

[6] Gonzales A, Quintana M, Matta C, Maldonado M. Frecuencia de diagnósticos y tratamientos pulpares según indicadores de la demanda realizados en una clínica dental universitaria. Rev. Estomatol Herediana 2005; 15 (2): 150 - 154.

[7] Gulsahi K, Gulsahi A, Ungor M, Genc Y. Frequency of root-filled teeth and prevalence of apical periodontitis in an adult Turkish population. Int Endod J. 2008; 41, 78-85.

[8] Jiménez-Pinzón A, Segura-EgeaJ-J, PoyatoFerrera M, Velasco-Ortega E, Rios-Santos JV. Prevalence of apical periodontitis and frecuency of root- filled teeth in an adult Spanish population. Int Endod J, 2004; 37, 167-173.

[9] Quadros I., Gomes B., Zaia A., Ferraz C., Souza-Filho F. Evaluation of Endodontic Treatments Performed by Students in a Brazilian Dental School. J Dent Ed. 2005; 69(10).

[10] Al-Omari MA, Hazaa A, and Haddad F. Frequency and distribution of root filled teeth and apical periodontitis in a Jordanian subpopulation Oral Surg Oral Med Oral Pathol Oral Radiol Endod 2011; 111:e59-65.

[11] Georgopoulou MK, Spanaki-Voreadi AP, Pantazis N, Kontakiotis EG. Frequency and distribution of root filled teeth and apical periodontitis in a Greek population. Int Endod J. 2005; 38:105-111.

[12] Hull TE, Robertson PB, Steiner JC, Michael A. Patterns of Endodontic Care for a 
Washington State Population. J Endod, 2003; 29(9).

[13] Cohen, Stephen \& Hargreaves, Kenneth M. VIAS DE LA PULPA. $9^{\circ}$ Edición. Editorial Elsevier Mosby. Madrid. 2008.

[14] Haapasalo M., Endal U., Zandi H. \& Coil J.Eradication of endodontic infection by instrumentation and irrigation solutions.Endodontic Topics 2005, 10, $77-$ 102.

[15] Leonardo MR. Endodoncia, tratamiento de conductos radiculares. Principios técnicos y biológicos. Volumen 1. Ed.Latinoamericana, 2005.

[16] I. Soares, F. Goldberg. Endodoncia. Técnica $\mathrm{y}$ fundamentos. 2003.

HOW TO CITE THIS ARTICLE

Alvarado V, Sepulveda G, Maiño D. Epidemiologic characterization of endodontic diagnosis and treatment. Appli. Sci. Dent. 2020; 1(1): 54-62. DOI: 10.22370/asd.2020.1.1.2116 